\title{
A influência de um sangradouro na distribuição espaço-temporal do isópode Tholozodium rhombofrontalis (Isopoda, Sphaeromatidae)
}

\author{
Larissa R. Pinto (1) \& Carlos A. Borzone (1)
}

Laboratório de Ecologia de Praias Arenosas, Centro de Estudos do Mar, Universidade Federal do Paraná. Caixa Postal 61, 83255-976, Pontal do Paraná, PR, Brasil. (larissa_guicho@yahoo.com.br; capborza@ufpr.br)

\author{
Recebido 17 maio 2018 \\ Aceito 20 novembro 2018 \\ Publicado 12 dezembro 2018
}

DOI 10.1590/1678-4766e2018043

\begin{abstract}
The influence of a washout in the spatio-temporal distribution of the isopod Tholozodium rhombofrontalis. The permanent freshwater discharges in sandy beaches, known as washouts, promotes changes in different spatial and temporal scales on the environmental characteristics, and consequently on macrobenthic populations. The aim of this study was to evaluate the changes of abundance, distribution and population structure of the isopod Tholozodium rhombofrontalis (Giambiagi, 1922) in a permanent washout. Seasonal samplings were realized in the Barrancos beach, Pontal do Paraná city, state of Paraná, southern Brazil, in three sites: on the washout (inside washout), intermediate (30 meters away from the washout), and distant (150 meters away from the washout), during four seasons of the years 2012 and 2013 . The beach was morphodynamically characterized as an intermediate beach, composed of fine and well sorted sediments. At the washout site the topographic profiles were smoother and longer, and the water table shallowed and fresh. In contrast, in the distant site the profiles were steeper and shorter, and the water table deeper and saline. The intermediate site presented characteristics similar to that of the washout. There was a spatial and temporal variability in the abundance and distribution of the isopod, being the greater abundances in the intermediate and washout sites, with peaks in the spring and summer seasons. These variations were related to the presence of brackish water and high values of chlorophyll $a$. The juveniles proportion were the higher of all classes, and remained temporally regular, indicating a continuous recruitment. The proportions of females remained similar temporally confirming the population stability. The proportion of males was low at all sites and during all samplings; however, the low representativeness of this class did not negatively affect the establishment of the population. The ovigerous females were present in all sites and in all samplings, with highest proportions in the winter, pointing to a possible preference for a colder season for reproduction. The presence of a permanent washout provided to this beach conditions of estuarine salinities, which possibly favored the establishment of the population.
\end{abstract}

KEYWORDS. Peracarida, freshwater discharge, exposed sandy beach, population structure.

RESUMO. As descargas de água doce permanentes em praias arenosas, conhecidas como sangradouros, promovem alterações em diferentes escalas espaciais e temporais sobre as características ambientais, e consequentemente sobre as populações macrobentônicas. O objetivo deste estudo foi avaliar as alterações da abundância, distribuição e estrutura populacional do isópode Tholozodium rhombofrontalis (Giambiagi, 1922) em um sangradouro permanente. Coletas sazonais foram realizadas na praia de Barrancos, cidade de Pontal do Paraná, estado do Paraná, sul do Brasil, em três locais: sangradouro (dentro do sangradouro), intermediário (a $30 \mathrm{~m}$ de distância do sangradouro) e distante (a $150 \mathrm{~m}$ de distância do sangradouro), durante as quatro estações dos anos de 2012 e 2013. A praia foi morfodinamicamente caracterizada como intermediária, composta de sedimentos finos e bem selecionados. No local sangradouro os perfis topográficos foram suaves e extensos, e o lençol freático raso e doce. Em contrapartida, no local distante os perfis foram íngremes e curtos, e o lençol freático profundo e salino. O local intermediário apresentou características similares ao do sangradouro. Houve uma variabilidade espacial e temporal na abundância e distribuição do isópode, estando as maiores abundâncias nos locais sangradouro e intermediário, com picos nas estações primavera e verão. Tais variações foram relacionadas à presença de águas salobras e altos valores de clorofila $a$. A proporção de juvenis foi a maior dentre todas as classes, e manteve-se regular temporalmente, indicando um recrutamento contínuo. As proporções de fêmeas mantiveram-se similares temporalmente confirmando a estabilidade da população. A proporção de machos foi baixa em todos os locais e durante todas as coletas, contudo, a baixa representatividade desta classe não afetou negativamente o estabelecimento da população. As fêmeas ovígeras estiveram presentes em todos os locais e em todas as coletas, com as maiores proporções no inverno, apontando uma possível preferência por uma estação mais fria para a reprodução. A presença de um sangradouro permanente proporcionou a esta praia condições de salinidade estuarina, o que possivelmente favoreceu o estabelecimento da população.

PALAVRAS-CHAVE. Peracarida, descarga de água doce, praia arenosa exposta, estrutura populacional.

As praias arenosas são caracterizadas por gradientes ambientais transversais e paralelos à linha de costa, influenciados por um conjunto de fatores físicos tais como amplitude de maré, altura e período das ondas, regime de ventos e granulometria, que interagem e resultam em constantes mudanças nos seus padrões hidrodinâmicos e deposicionais (SHORT, 1999). Por sua vez, as populações macrobentônicas destes ambientes apresentam padrões dinâmicos na abundância, na estrutura etária e no potencial de recrutamento em distintas escalas espaciais e também 
temporais, geralmente resultantes de gradientes físicos e variações sazonais (BrazeIro \& DEFEO, 1996; MCLACHLAN, 1996; Dugan \& McLachlan, 1999; Lercari \& Defeo, 2006).

As descargas de água doce no ambiente praial têm sido estudadas por afetarem os regimes de nutrientes e também as características do habitat e da biota residente, em decorrência da formação de gradientes de salinidade (SANTOS, 1991; LERCARI et al., 2002; SCHOEMAN \& RichARDSON, 2002; GANDARA-MARTINS et al., 2015). Estas descargas podem ocorrer através de rios (CISNEROS et al., 2011), canais de drenagem artificiais (LERCARI \& DEFEO, 2003) ou por meio de sangradouros, que são definidos como canais de drenagem natural da água resultante do acúmulo pluviométrico na região do pós-dunas (Pereira da Silva et al., 2003).

Os isópodes da família Sphaeromatidae estão adaptados a mudanças de salinidade, ocorrendo em ambientes polihalino, mesohalino e também semiterrestres (LoyolA E Silva, 1960). Em particular, o isópode Tholozodium rhombofrontalis (GiamBIAGI, 1922) foi descrito em praias de águas salobras e solo constituído de areia e silte do rio Quequén, Argentina. Ao longo do Rio de la Plata, este isópode foi encontrado em solos arenosos e salinidades muito oscilantes, desde águas doces a salobras, sendo classificado como uma espécie estuarina (BosCHI, 1988; DARRIGRAN \& RIOJA, 1988; TABERNER, 1988; Wells \& DABORN, 1998; César et al., 2000). A dieta de T. rhombofrontalis ainda não é totalmente conhecida, no entanto, ElEFTHERIOU et al. (1980), em um trabalho conduzido em praias arenosas da Índia, determinaram através de análises do conteúdo estomacal que Tholozodium ocellatum Eleftheriou, Holdich \& Harrison, 1980 apresenta dieta herbívora e provavelmente onívora, baseada em partículas orgânicas depositadas nas áreas superiores da praia.

A presença de Tholozodium rhombofrontalis no Brasil foi relatada pela primeira vez para a Ilha do Mel, Paraná, em um riacho de água salobra e entre restos de vegetais (Loyola e Silva, 1960). O primeiro registro em praias arenosas expostas foi o de Souza \& Gianuca (1995) no litoral do estado do Paraná. Ao longo da costa sul e sudeste do Brasil, regiões que não apresentam uma estação seca definida e que sofrem influência de eventos climáticos aperiódicos, outras ocorrências desta espécie foram relatadas tanto em ambientes de água doce, como em praias estuarinas e também em praias arenosas oceânicas (PIRES, 1982; VAROLI, 1990; Würdig \& DORnelles DA SiLVA, 1990; Borzone et al., 1996; Borzone \& SouzA, 1997; FLYNn et al., 1998; Borzone et al., 2003; СосHÔA et al., 2006; VIEIRA et al., 2012; Felix et al., 2015; GANDARA-MARTINS et al., 2015). Nenhum destes relatos inclui uma descrição da estrutura populacional de Tholozodium rhombofrontalis, sendo incerto se a ocorrência em tão variados ambientes corresponde apenas a registros pontuais e de poucos exemplares ou a populações bem estabelecidas.

De certa maneira, os sangradouros em praias oceânicas representam um excelente local para determinar a relação da espécie com o ambiente límnico. Neste sentido, o objetivo deste estudo foi analisar os padrões espaciais e temporais da abundância, distribuição e estrutura da população de Tholozodium rhombofrontalis em uma praia arenosa oceânica sob a influência de um sangradouro permanente.

\section{MATERIAL E MÉTODOS}

Área de estudo. A praia de Barrancos está localizada cerca de $8 \mathrm{~km}$ ao sul da desembocadura da Baía de Paranaguá, Paraná, fazendo parte de uma faixa de $30 \mathrm{~km}$ de praia ininterrupta (SouZa \& GiANUCA, 1995), conhecida como Planície de Praia de Leste (Borzone et al., 1996) (Fig. 1). Essa região é caracterizada por praias compostas por areia quartzosa, de granulometria fina a média, bem selecionada, com declividades variando entre $1^{\circ}$ e $5^{\circ}$ e com formação de um ou dois bancos de espraiamento em média (Angulo \& AraúJo, 1996). Souza \& Gianuca (1995) classificaram Barrancos como uma praia de estado morfodinâmico dissipativo. Segundo Borzone \& SouzA (1997) a praia de Barrancos está livre da influência do delta de vazante do estuário, contudo, nesta praia encontra-se o sangradouro permanente de Barrancos, o qual apresenta um fluxo praticamente constante de água doce (GANDARAMARTINs et al., 2015).

Coleta e processamento de dados. As amostragens foram realizadas no verão, outono, inverno e primavera dos anos de 2012 e 2013, sempre em maré baixa de sizígia. Ao longo da praia foram selecionados três locais de coleta: sangradouro (dentro do sangradouro), intermediário (a $30 \mathrm{~m}$ de distância do sangradouro) e distante (a $150 \mathrm{~m}$ de distância do sangradouro), sendo os mesmos fixados a cada coleta. Em cada local foram dispostas três transecções distanciadas em $3 \mathrm{~m}$, sendo posicionados, em cada transecção, doze pontos amostrais distribuídos em desníveis equidistantes (\#-2 ao \#9) desde a base das dunas primárias até a marca da última maré baixa, sendo o nível \#0 situado na marca da linha de deposição de detritos em todos os locais (Fig. 2). O uso de desníveis equidistantes para o estabelecimento dos pontos de coleta permitiu amostrar zonas praiais similares independentemente da largura da praia nos diferentes locais.

Para a caracterização topográfica dos três locais amostrados ao longo das oito coletas foram mensurados os perfis topográficos com auxílio de um nível de precisão e de uma régua graduada. Para o cálculo do estado morfodinâmico foram observados em campo os dados do regime de ondas incidentes, como descrito em VIEIRA et al. (2012). A mensuração da profundidade e da salinidade do lençol freático, bem como a coleta e o processamento das amostras de sedimento para análise do tamanho médio do grão, do grau de seleção, da porcentagem de carbonatos e da porcentagem de matéria orgânica, foram feitas conforme descrito em GANDARA-MARTINs et al. (2015), e realizadas na transecção central e em cada nível de cada local (Fig. 2). Para quantificar a concentração de clorofila $a$ foi coletada uma amostra do sedimento superficial na transecção central e em cada nível de cada local (Fig. 2), e posteriormente, em 


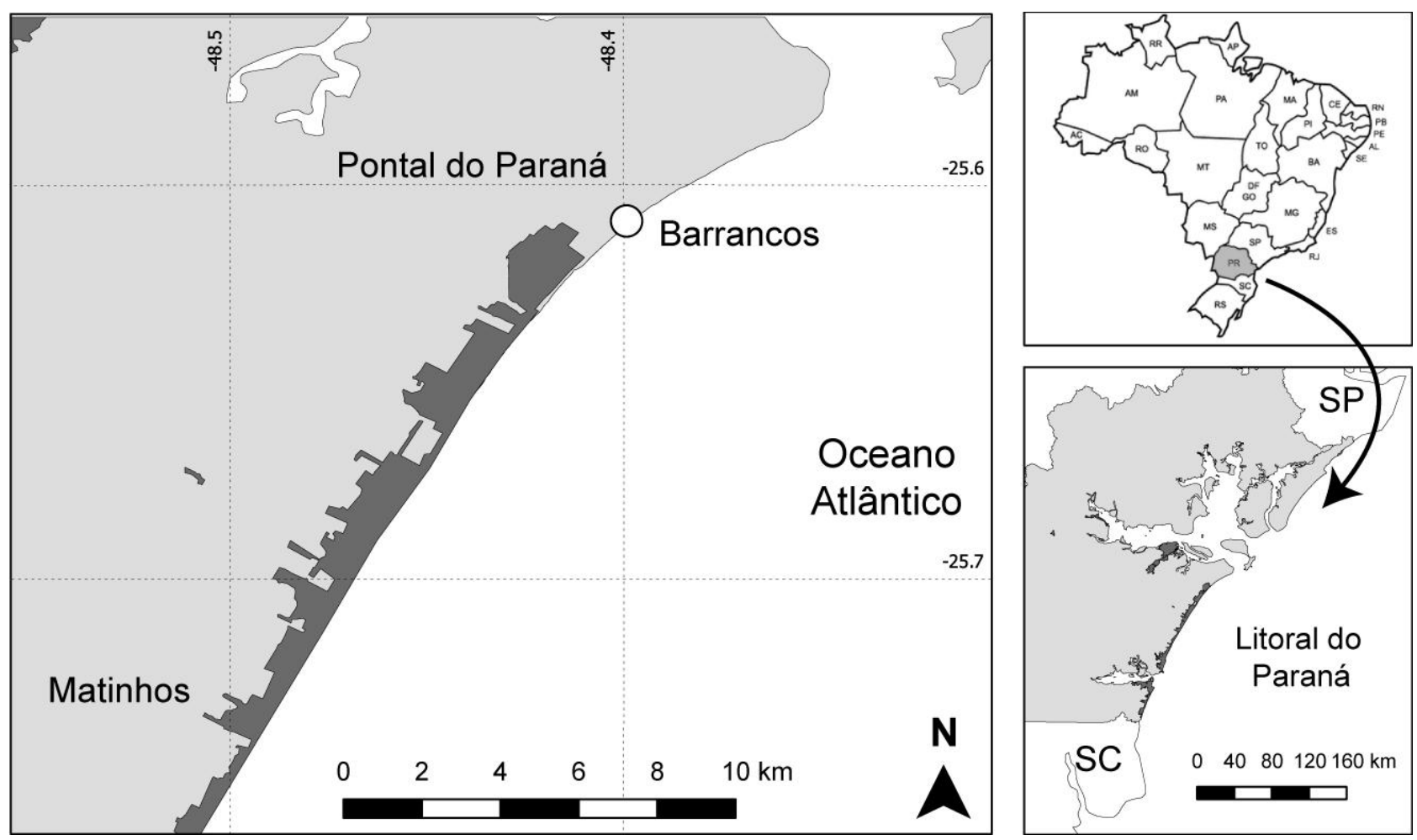

Fig. 1. Mapa da Planície de Praia de Leste, região central do litoral do Paraná, Brasil. Em destaque a localização da praia de Barrancos $\left(25^{\circ} 36^{\prime} 32,6^{\prime \prime} \mathrm{S}, 48^{\circ} 23^{\prime} 59,3^{\prime \prime} \mathrm{W}\right)$.

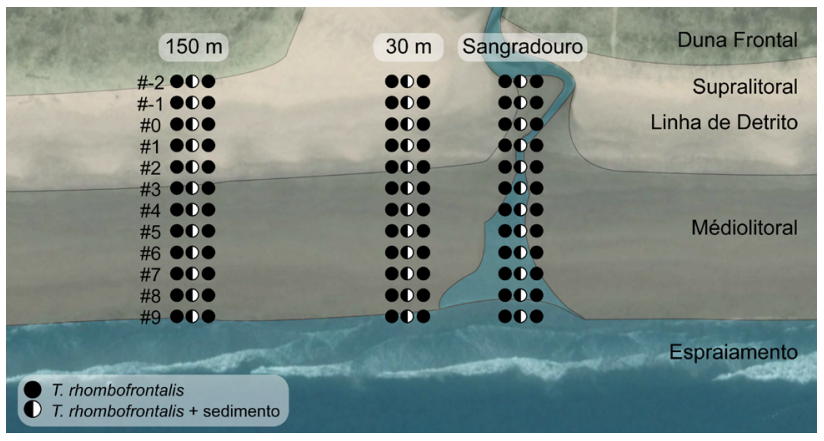

Fig. 2. Delineamento amostral adotado nas coletas de dados ambientais e biológicos realizadas nos anos de 2012 e de 2013, na praia de Barrancos, Paraná, Brasil. As distâncias representadas na figura não são proporcionais. Locais: distante $(150 \mathrm{~m})$, intermediário $(30 \mathrm{~m})$ e sangradouro. Níveis: \#-2 ao \#9, sendo o nível \#0 disposto na linha de deposição de detritos. Círculos pretos representam a coleta de Tholozodium rhombofrontalis (Giambiagi, 1922). Círculos preto/branco na transecção central representam a coleta de T. rhombofrontalis e a coleta de amostras de sedimento para a análise dos dados ambientais.

laboratório, processadas seguindo o método colorimétrico de Strickland \& PARsons (1972).

Para as coletas de Tholozodium rhombofrontalis foram tomadas amostras nas três transecções e em cada nível de cada local, com um cilindro de ferro de $25 \mathrm{~cm}$ de diâmetro enterrado no sedimento a $20 \mathrm{~cm}$ de profundidade (Fig. 2). Cada volume de sedimento foi transferido para um saco de malha de $0,5 \mathrm{~mm}$ e lavado in situ. O material retido na malha foi acondicionado em saco plástico identificado e fixado em formalina $10 \%$. No laboratório os organismos foram contabilizados e armazenados em álcool 70\%.
Para as análises da estrutura da população foram tomadas subamostras do material obtido na transecção central de cada local, em uma escala de no máximo cem indivíduos por nível. Os organismos foram medidos desde a extremidade do rostro até o final do pleotelson para determinar o comprimento, a largura foi mensurada a partir da medição do $5^{\circ}$ pereonito e a classificação sexual foi definida pela presença ou ausência do apêndice masculino, o qual é localizado no $2^{\circ}$ pleópodo (TABERNER, 1988). A partir disso, os indivíduos foram ordenados nas seguintes classes: juvenil, fêmea, macho e fêmea ovígera.

A fim de identificar quais os parâmetros que determinam as características ambientais de cada local e sua relação temporal foi realizada uma Análise de Componentes Principais (ACP) (VALENTIN, 2000) com os valores normalizados da elevação $(\mathrm{m})$, profundidade do lençol freático $(\mathrm{m})$, largura total da praia $(\mathrm{m})$, declividade do perfil praial $\left({ }^{\circ}\right)$, estado morfodinâmico $(\Omega)$, tamanho médio do grão (mm), matéria orgânica (\%), salinidade do lençol freático e concentração de clorofila $a(\mu \mathrm{g} / \mathrm{g})$. Os dados de grau de seleção $(\phi)$ e carbonatos (\%) não foram utilizados nesta análise devido à alta colinearidade com outros parâmetros.

Foram gerados mapas de superfície através do método de interpolação "krigagem" (CRESSIE, 1990) para visualizar os padrões espaciais e temporais da salinidade do lençol freático, da concentração de clorofila $a$ disponível no sedimento e também dos padrões de abundância, distribuição e estrutura populacional de Tholozodium rhombofrontalis.

Diferenças espaciais e temporais na abundância total média da população foram identificadas por 
meio de Análises de Variância Multifatorial (ANOVA multifatorial) (UNDERWOOD, 1997). A homocedasticidade e a normalidade dos dados foram verificadas pelos testes de Levene e de Shapiro-Wilk, respectivamente. Os dados foram transformados em $(\log (\mathrm{x}+1))$ para atenderam aos pressupostos da ANOVA. O modelo linear incluiu os seguintes fatores: local (fixo, ortogonal, três níveis: "distante", "intermediário" e "sangradouro"), nível (fixo, ortogonal, com doze níveis: "\#-2" ao "\#9"), estação (fixo, ortogonal, com quatro níveis: "verão", "outono", "inverno" e "primavera"), ano (aleatório, ortogonal, com dois níveis: "2012" e "2013") e as interações entre os fatores. Quando diferenças significativas foram detectadas após a realização da ANOVA $(\mathrm{p}<0,05)$, estas foram discriminadas através do teste post-hoc de Student-Newman-Keuls (teste SNK). As análises foram realizadas no software R Studio, com auxílio do pacote GAD (SANDRINI-Neto \& CAMARGO, 2011).

\section{RESULTADOS}

Caracterização ambiental. O local sangradouro mostrou os perfis topográficos mais extensos e mais suaves em todas as estações durante os dois anos (Fig. 3; Tab. I). Concomitantemente, o lençol freático no sangradouro apresentou o perfil mais raso quando comparado aos demais locais, acompanhando o perfil praial em grande parte da sua extensão (Fig. 4). Em contraposição, o local distante apresentou os perfis topográficos mais estreitos e mais íngremes (Fig. 3; Tab. I) e os maiores valores de profundidade do lençol freático, com exceção do verão de 2013 (Fig. 4). Como esperado, o local intermediário mostrou características intermédias, com maior semelhança ao sangradouro nas coletas de inverno e primavera (Figs 3, 4; Tab. I).

Como observado na ACP, o sangradouro mostrou grande variação das características ambientais entre as coletas, contudo as baixas profundidades e salinidades do lençol freático determinaram a separação dos demais locais. Ocorreu também uma separação sazonal, onde as coletas do verão e da primavera de 2012 apresentaram altas concentrações de clorofila $a$ e baixas concentrações foram exibidas nas mesmas estações do ano de 2013 (Fig. 5). No local distante houve um padrão sazonal, com o verão e a primavera de 2012 e 2013 apresentando as maiores declividades e o outono e inverno de ambos os anos as maiores salinidades (Fig. 5). Este padrão foi similar àquele registrado no local intermediário, onde o verão se manteve associado ao estado morfodinâmico e a declividade do perfil praial e o inverno à concentração de clorofila $a$ em ambos os anos. O outono de 2012 e a primavera de 2013 seguiram os padrões do verão em ambos os anos, enquanto a primavera de 2012 e o outono de 2013 apresentaram maiores concentrações de clorofila $a$, assim como no inverno dos dois anos (Fig. 5).

Todos os perfis topográficos amostrados apresentaram estados morfodinâmicos intermediários, com exceção do verão de 2013, no qual houve um registro de estado morfodinâmico dissipativo nos locais sangradouro e intermediário (Tab. I).

O sedimento foi classificado como areia fina e bem selecionado (Fig. 6) em todos os locais durante todas as estações dos dois anos. Em 2012 houve maior variação espacial na porcentagem de carbonatos e de matéria orgânica, enquanto que em 2013 estas porcentagens resultaram similares entre os locais e as estações do ano (Fig. 6).

Os valores mais altos da salinidade do lençol freático foram obtidos nos locais distante e intermediário, entre os níveis \#7 ao \#9. Em contrapartida, no sangradouro a salinidade foi sempre baixa em todos os níveis e em todas as coletas. A salinidade não apresentou diferenças notáveis entre as estações e entre os anos, com exceção do verão de 2013, onde foram registrados nos três locais valores baixos nos níveis mais próximos ao mar (Fig. 7). Foi observada maior concentração de clorofila $a$ nos locais sangradouro e intermediário, principalmente entre os níveis \#-2 ao \#4. No local distante a concentração de clorofila $a$ foi menor, porém distribuída similarmente entre todos os níveis durante as oito coletas (Fig. 7).

Padrões de abundância, distribuição e estrutura da população de Tholozodium rhombofrontalis. Um total de 47.323 indivíduos foi coletado ao longo das oito amostragens, sendo que deste total $23,26 \%$ foi obtido no local distante, $40,92 \%$ no intermediário e $35,82 \%$ no sangradouro. Deste total, 38,96\% foi registrado em 2012 e 61,04\% em 2013.

A ANOVA - multifatorial indicou diferenças nos padrões espaciais e temporais da abundância total média de Tholozodium rhombofrontalis em todos os fatores (local, nível, estação e ano) e suas interações (Fig. 8; Tab. II). No

Tab. I. Valores de largura total da praia, declividade do perfil topográfico e estado morfodinâmico dos três locais de coleta (distante, intermediário e sangradouro) ao longo das oito amostragens realizadas na praia de Barrancos, Paraná, Brasil. Parâmetros de Dean: $\Omega<1$ - praias reflectivas, $1 \leq \Omega \leq 6$ praias intermediárias e $\Omega>6$ - praias dissipativas.

\begin{tabular}{|c|c|c|c|c|c|c|c|c|c|}
\hline \multirow{2}{*}{ Estação/Ano } & \multicolumn{3}{|c|}{ Largura total (m) } & \multicolumn{3}{|c|}{ Declividade $\left({ }^{\circ}\right)$} & \multicolumn{3}{|c|}{ Parâmetro de Dean $\Omega$ ) } \\
\hline & Dist. & Inter. & Sang. & Dist. & Inter. & Sang. & Dist. & Inter. & Sang. \\
\hline Verão/2012 & 109,1 & 130,1 & 168,7 & 1,29 & 0,92 & 0,72 & 3,29 & 3,17 & 3,07 \\
\hline Outono/2012 & 116,8 & 131,4 & 153,4 & 1,10 & 0,72 & 0,81 & 3,25 & 3,02 & 2,91 \\
\hline Inverno/2012 & 126,9 & 164,0 & 188,2 & 1,24 & 0,74 & 0,67 & 3,96 & 4,09 & 4,31 \\
\hline Prim./2012 & 125,8 & 165,3 & 179,2 & 1,22 & 0,67 & 0,48 & 1,78 & 1,97 & 2,20 \\
\hline Verão/2013 & 84,6 & 121,4 & 141,4 & 1,42 & 0,95 & 0,59 & 4,81 & 6,18 & 6,06 \\
\hline Outono/2013 & 102,0 & 114,2 & 157,9 & 1,44 & 1,16 & 0,61 & 3,17 & 3,55 & 4,06 \\
\hline Inverno/2013 & 117,1 & 150,4 & 169,9 & 1,22 & 0,73 & 0,65 & 2,07 & 2,69 & 2,80 \\
\hline Prim./2013 & 75,4 & 113,9 & 94,5 & 1,65 & 0,78 & 1,05 & 4,54 & 4,28 & 4,64 \\
\hline
\end{tabular}



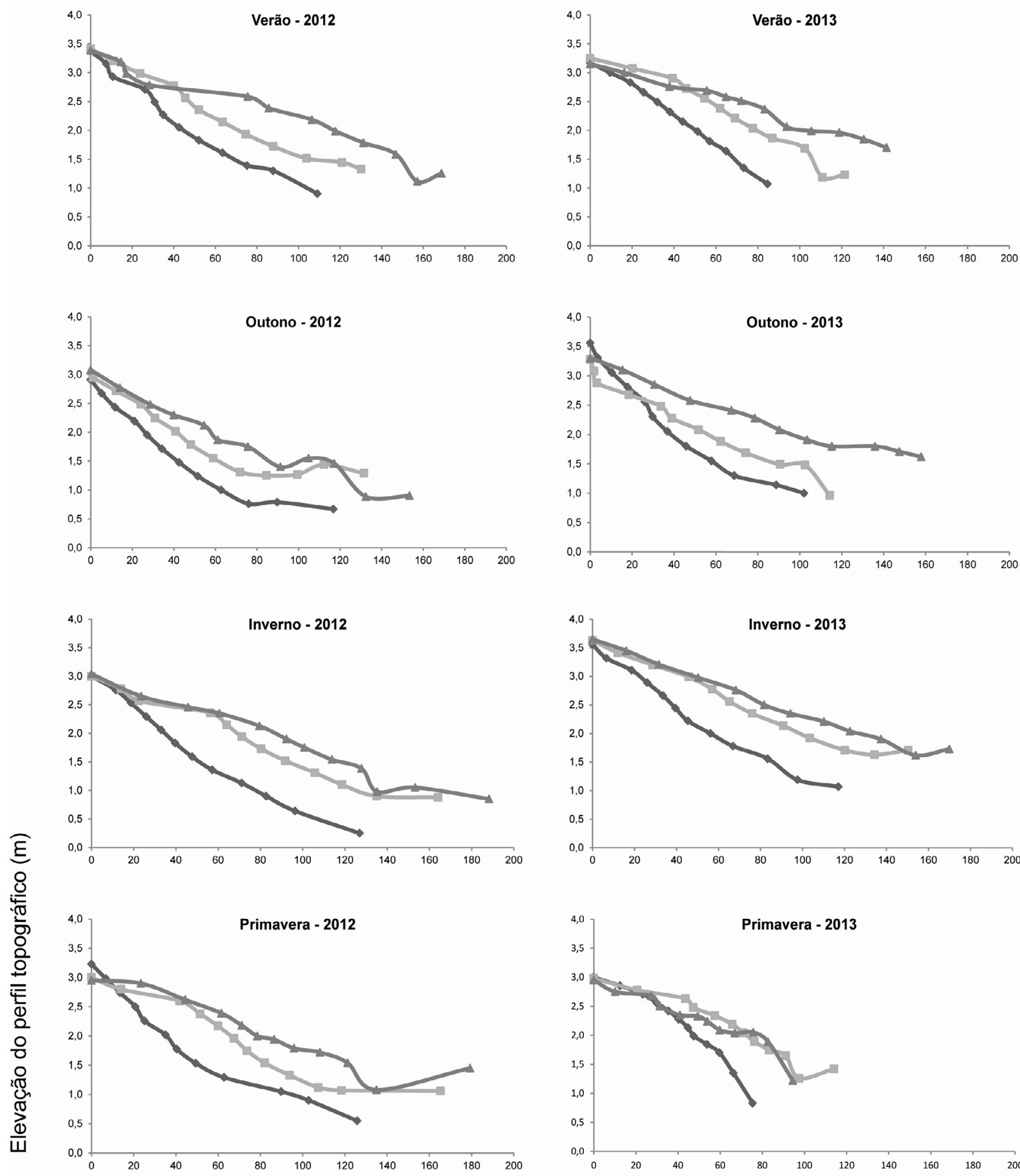

Largura do perfil topográfico $(\mathrm{m})$

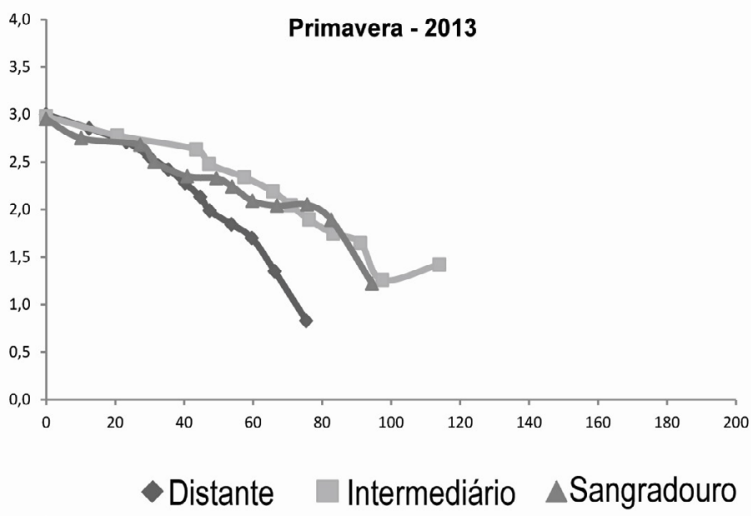

Fig. 3. Perfil topográfico dos três locais de coleta (distante, intermediário e sangradouro) ao longo das oito amostragens realizadas na praia de Barrancos, Paraná, Brasil. 

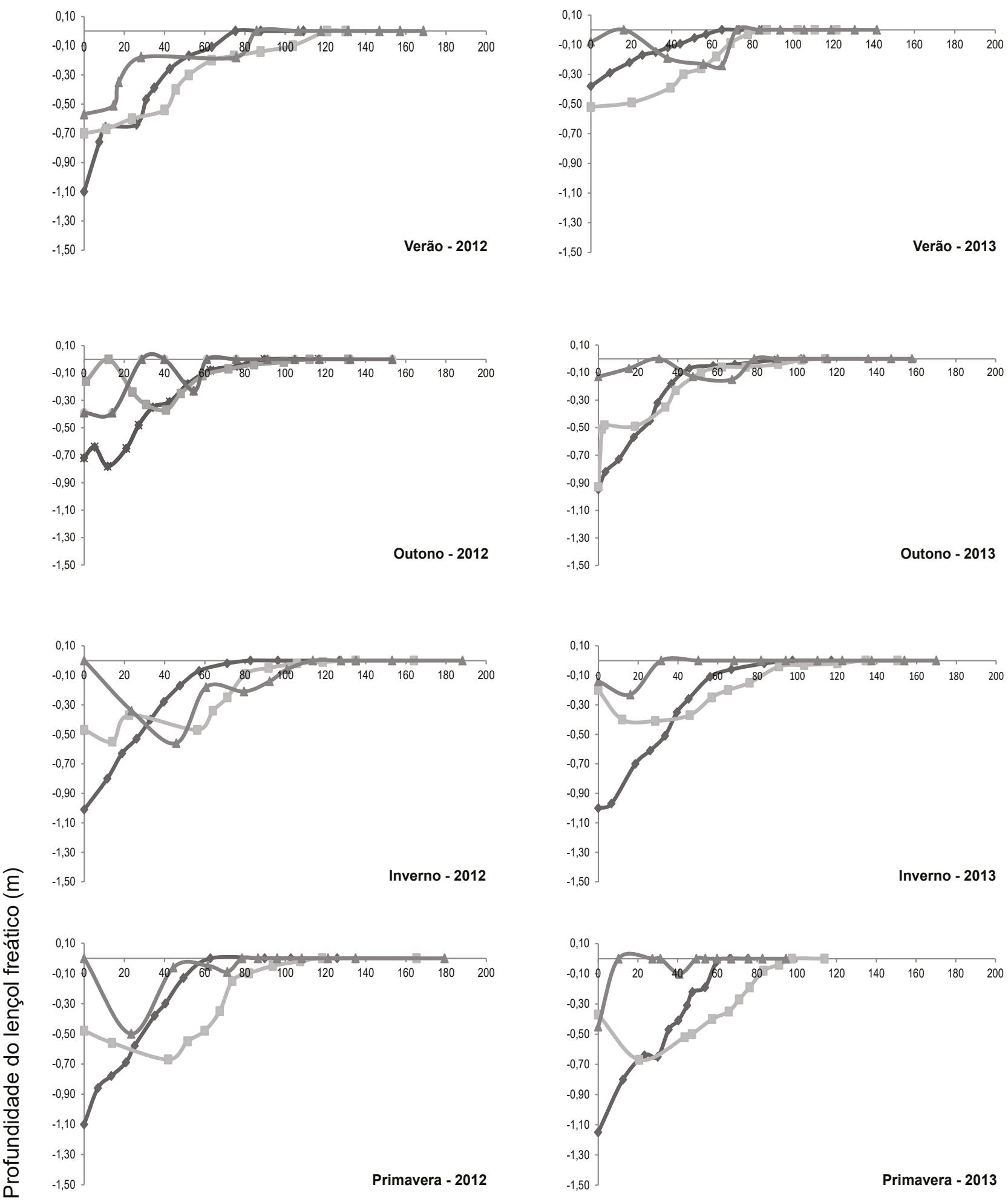

Largura do perfil topográfico $(m)$

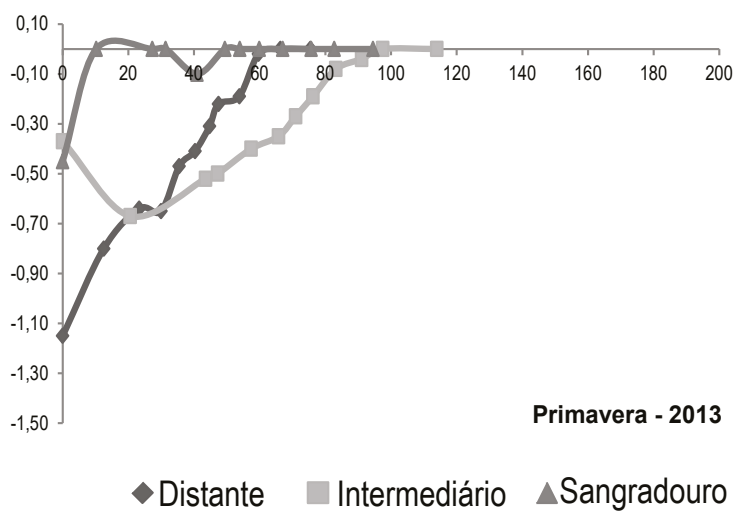

Fig. 4. Perfil da profundidade do lençol freático dos três locais de coleta (distante, intermediário e sangradouro) ao longo das oito amostragens realizadas na praia de Barrancos, Paraná, Brasil. 


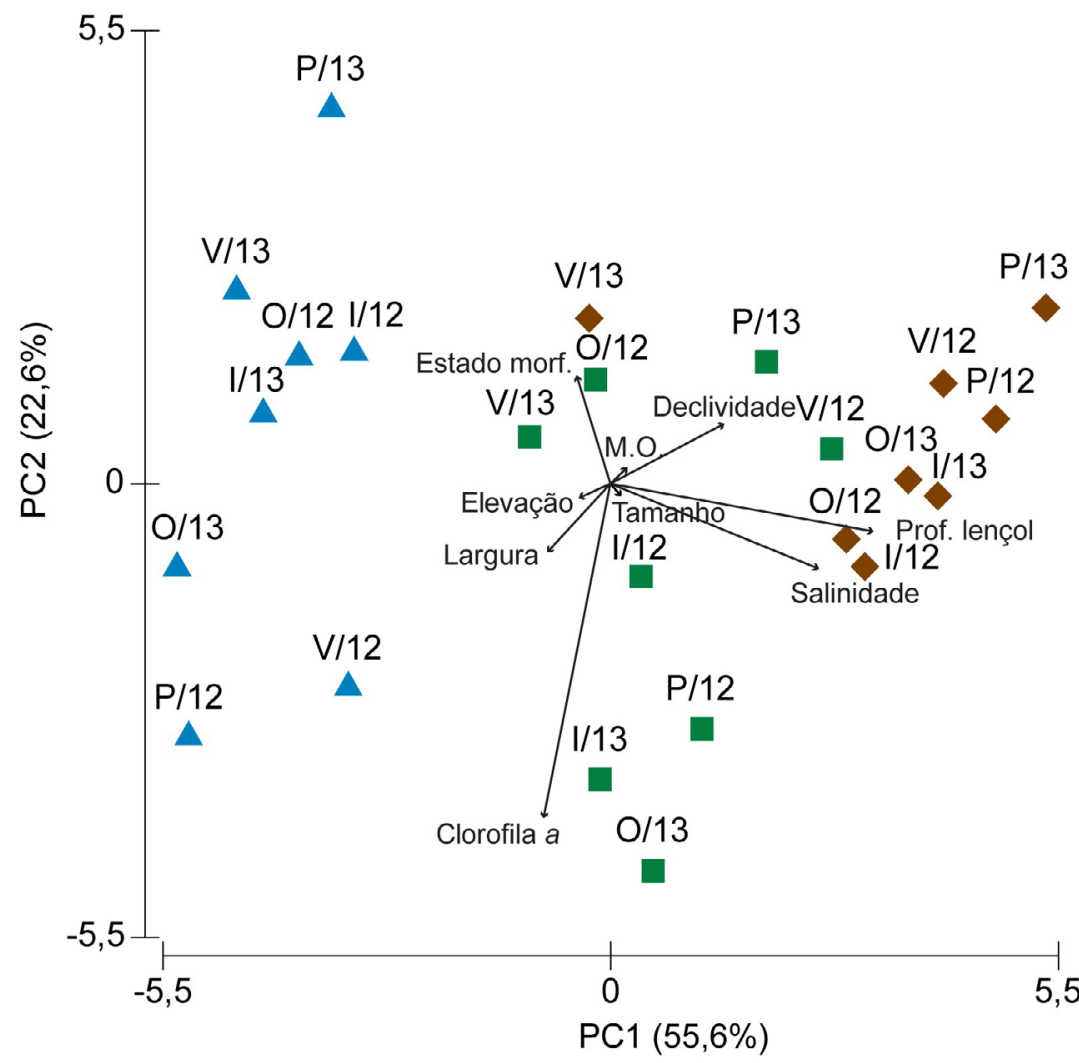

Fig. 5. Análise de Componentes Principais (ACP) dos dados ambientais coletados ao longo das oito amostragens realizadas na praia de Barrancos, Paraná, Brasil. As setas representam a contribuição de cada variável ambiental na variância total das duas primeiras componentes. Os símbolos coloridos representam os três locais de coleta: distante (losango marrom), intermediário (quadrado verde) e sangradouro (triângulo azul). As amostragens $(\mathrm{n}=8)$ estão identificadas como: verão de 2012 (V/12), outono de 2012 (O/12), inverno de 2012 (I/12), primavera de 2012 (P/12), verão de 2013 (V/13), outono de $2013(\mathrm{O} / 13)$, inverno de 2013 (I/13) e primavera de $2013(\mathrm{P} / 13)$.
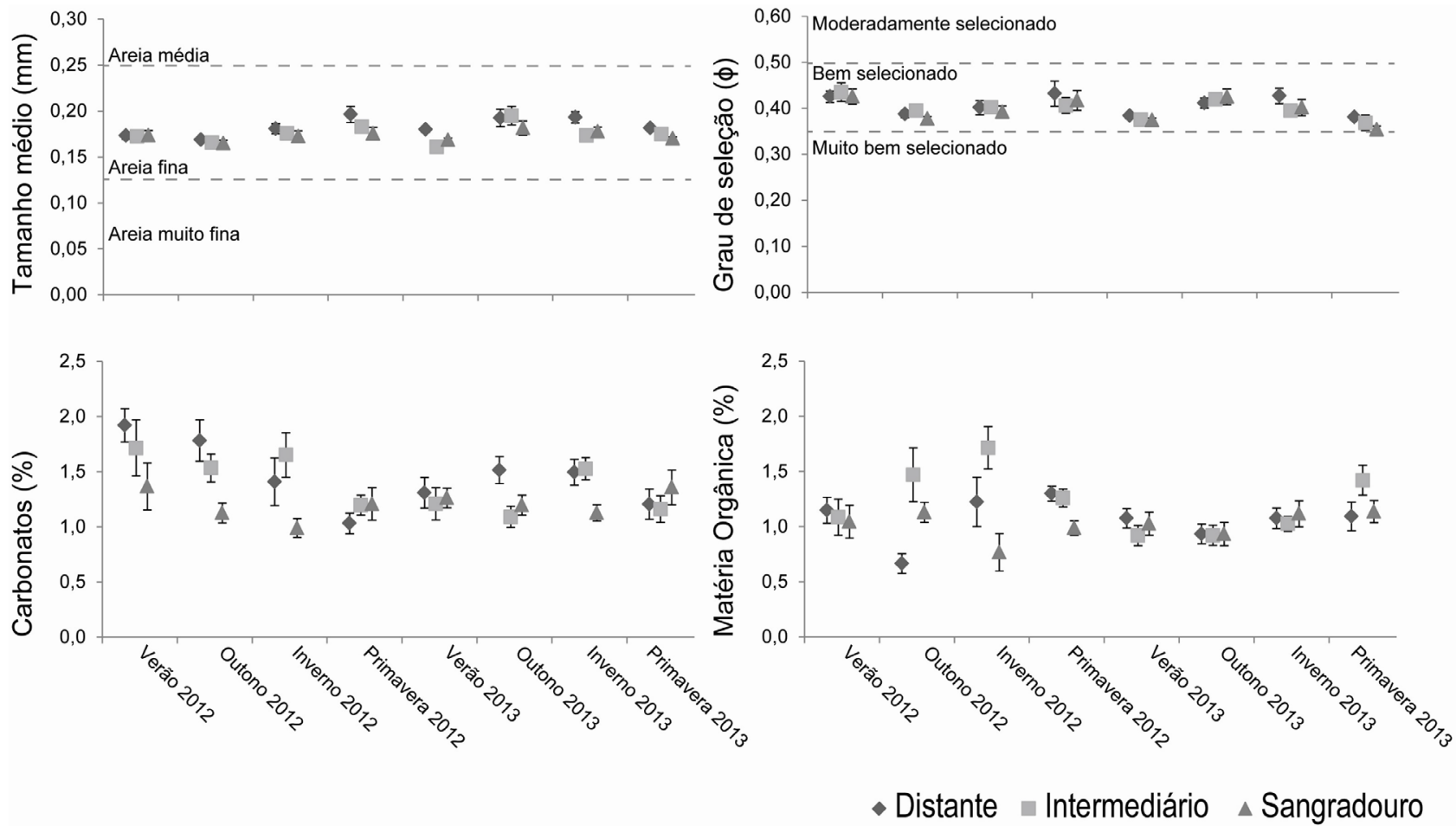

Fig. 6. Média e erro padrão do tamanho médio do grão, do grau de seleção, da porcentagem de carbonatos e da porcentagem de matéria orgânica dos três locais de coleta (distante, intermediário e sangradouro) ao longo das oito amostragens realizadas na praia de Barrancos, Paraná, Brasil. Para o cálculo da média e do erro padrão foram utilizados os dados de todos os níveis. 


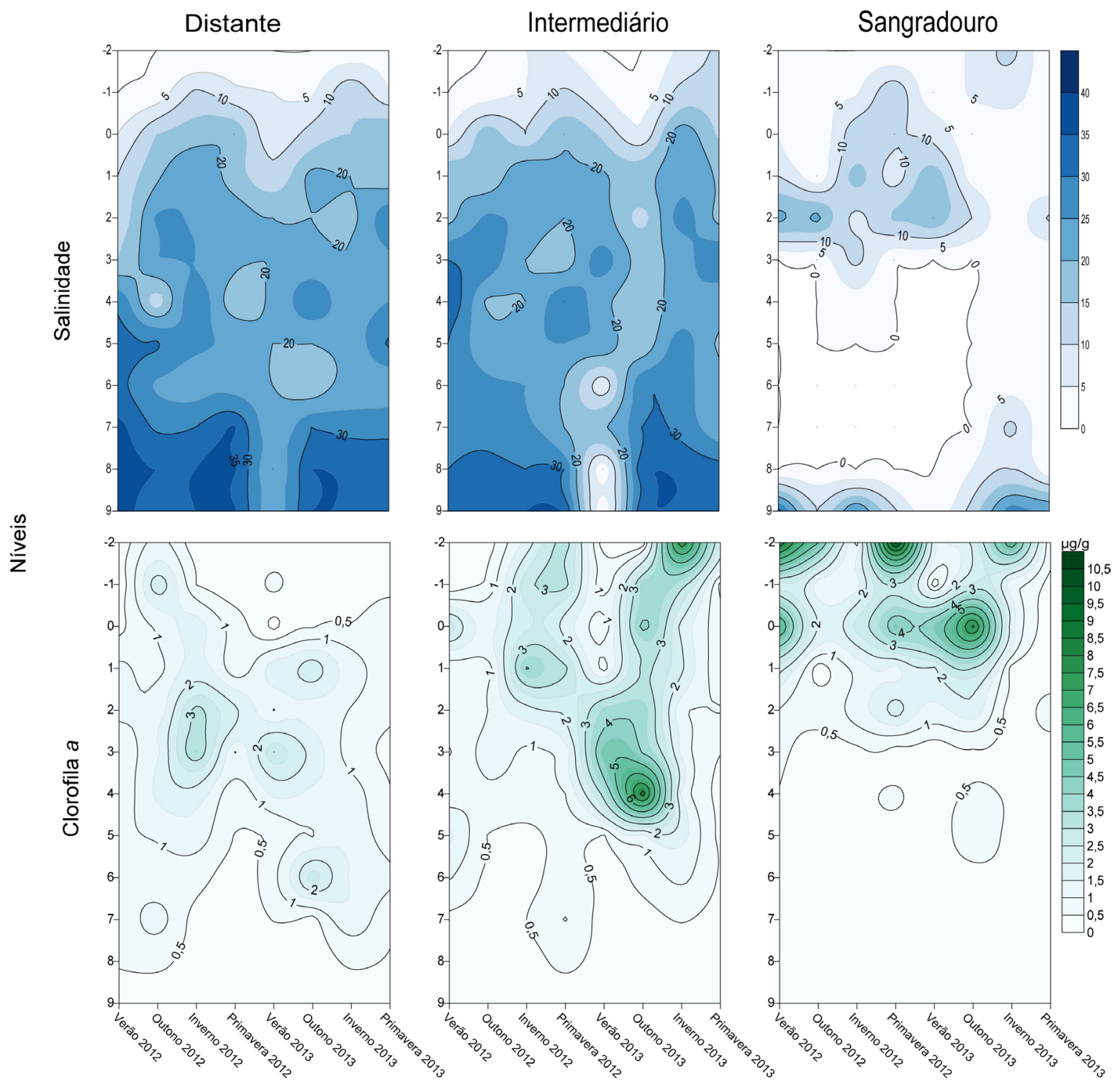

Fig. 7. Valores da salinidade do lençol freático e da concentração de clorofila $a$ no sedimento $(\mu \mathrm{g} / \mathrm{g})$ dos três locais de coleta (distante, intermediário e sangradouro) ao longo dos níveis e das oito amostragens realizadas na praia de Barrancos, Paraná, Brasil.

local distante, a maior ocorrência da espécie esteve restrita entre a faixa da linha de deposição de detritos e a zona mediolitoral superior, com maiores abundâncias no inverno e primavera de 2013 (ANOVA $<<0,001$; teste SNK; Fig. 8). No local intermediário houve uma distribuição mais ampla entre a linha de deposição de detritos e a zona mediolitoral inferior, e as maiores abundâncias ocorreram a partir da primavera de 2012 (ANOVA $p<0,001$; teste SNK; Fig. 8). No local sangradouro a distribuição apresentou ocorrência mais dispersa entre os níveis quando comparada aos demais locais, ocupando desde a base das dunas primárias até o mediolitoral inferior, com altas abundâncias no verão e na primavera do ano de 2012 e nas estações outono, inverno e primavera de 2013 (ANOVA p $<0,001$; teste SNK; Fig. 8).

De um total de 9.120 indivíduos classificados pelo sexo e pelo estágio de desenvolvimento $40 \%$ resultaram em juvenis, $33,1 \%$ em fêmeas, $16 \%$ em machos e $10,9 \%$ em fêmeas ovígeras.
Os juvenis estiveram presentes em todos os locais, embora no sangradouro tenha mostrado um aparecimento irregular. Nos locais intermediário e distante, os indivíduos juvenis apresentaram maior proporção e regularidade ao longo das estações e em ambos os anos de coleta, exceto por uma redução no inverno de 2013 no local distante (Fig. 9).

As fêmeas mostraram um padrão de distribuição muito similar ao dos juvenis, com as maiores proporções no local distante. Machos e fêmeas ovígeras apareceram em proporções menores e irregulares durante as oito coletas, geralmente restritos aos níveis \#1 ao \#4. A proporção de fêmeas ovígeras ocorreu de maneira semelhante nos locais distante e sangradouro; no local intermediário, a presença desta classe foi consideravelmente menor. Ao longo do tempo, as maiores proporções de fêmeas ovígeras foram registradas durante o verão e inverno, particularmente no local distante, o qual manteve tal padrão nos dois anos de coleta (Fig. 9). 


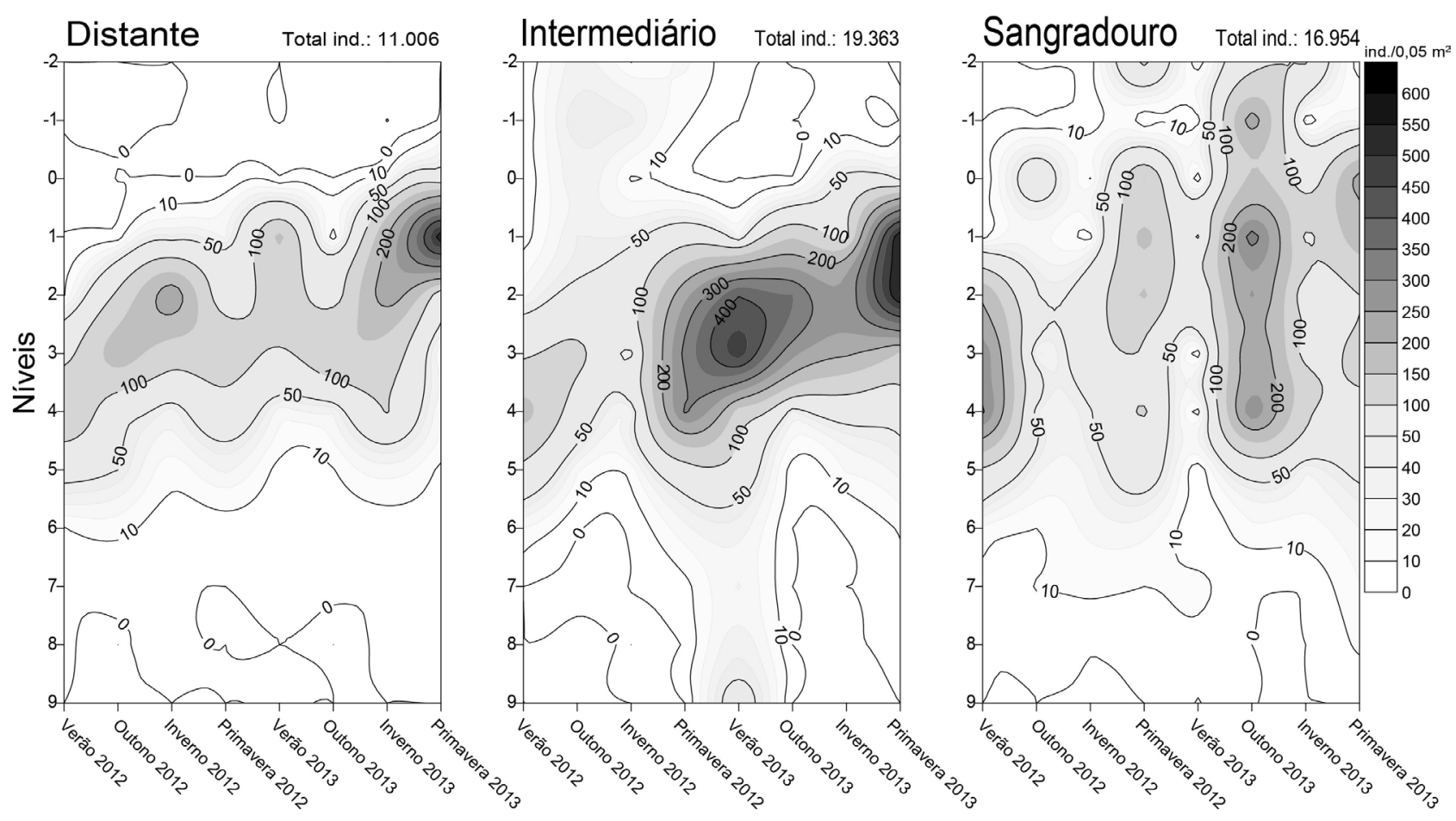

Fig. 8. Abundância total média de Tholozodium rhombofrontalis (Giambiagi, 1922) (ind./0,05 m²) registrada nos três locais de coleta (distante, intermediário e sangradouro) ao longo dos níveis e das oito amostragens realizadas na praia de Barrancos, Paraná, Brasil. A abundância total média foi calculada através da média das três transecções dispostas em cada nível de cada local.

Tab.II. Resultados da ANOVA - multifatorial da abundância total de Tholozodium rhombofrontalis, (GiamBIAGI, 1922) considerando os fatores: local (fixo, ortogonal, três níveis: "distante", "intermediário" e "sangradouro"), nível (fixo, ortogonal, com doze níveis: “\#-2" ao "\#9”), estação (fixo, ortogonal, com quatro níveis: "verão", "outono", "inverno" e "primavera"), ano (aleatório, ortogonal, com dois níveis: "2012” e "2013"). Siglas: G.L. (Grau de Liberdade), Q.M. (Quadrado Médio), F (Valor de F), p (valor de p), n.s. (não significativo, p > 0,05).

\begin{tabular}{lcccc}
\hline Fatores e interações & G.L. & Q.M. & F & p \\
\hline Local & 2 & 50,264 & 460,8746 & $<0,01$ \\
Nível & 11 & 176,238 & 19,8197 & $<0,001$ \\
Estação & 3 & 21,018 & 19,2292 & $<0,05$ \\
Ano & 1 & 8,071 & 18,9783 & $<0,001$ \\
Local*Nível & 22 & 4,998 & 1,4507 & n.s. \\
Local*Estação & 6 & 11,560 & 0,7288 & n.s. \\
Nível*Estação & 33 & 6,022 & 1,2061 & n.s. \\
Local*Ano & 2 & 0,109 & 0,2564 & $<. s$. \\
Nível*Ano & 11 & 8,892 & 20,9082 & $<0,001$ \\
Estação*Ano & 3 & 1,093 & 2,5700 & n.s. \\
Local*Nível*Estação & 66 & 3,055 & 1,1775 & $<0,001$ \\
Local*Nível*Ano & 22 & 3,445 & 8,1013 & $<0,001$ \\
Local*Estação*Ano & 6 & 15,862 & 37,2965 & $<0,001$ \\
Nível*Estação*Ano & 33 & 4,993 & 11,7408 & $<0,001$ \\
Local*Nível*Estação*Ano & 66 & 2,594 & 6,1000 & \\
Residual & 576 & 0,425 & & \\
\hline
\end{tabular}




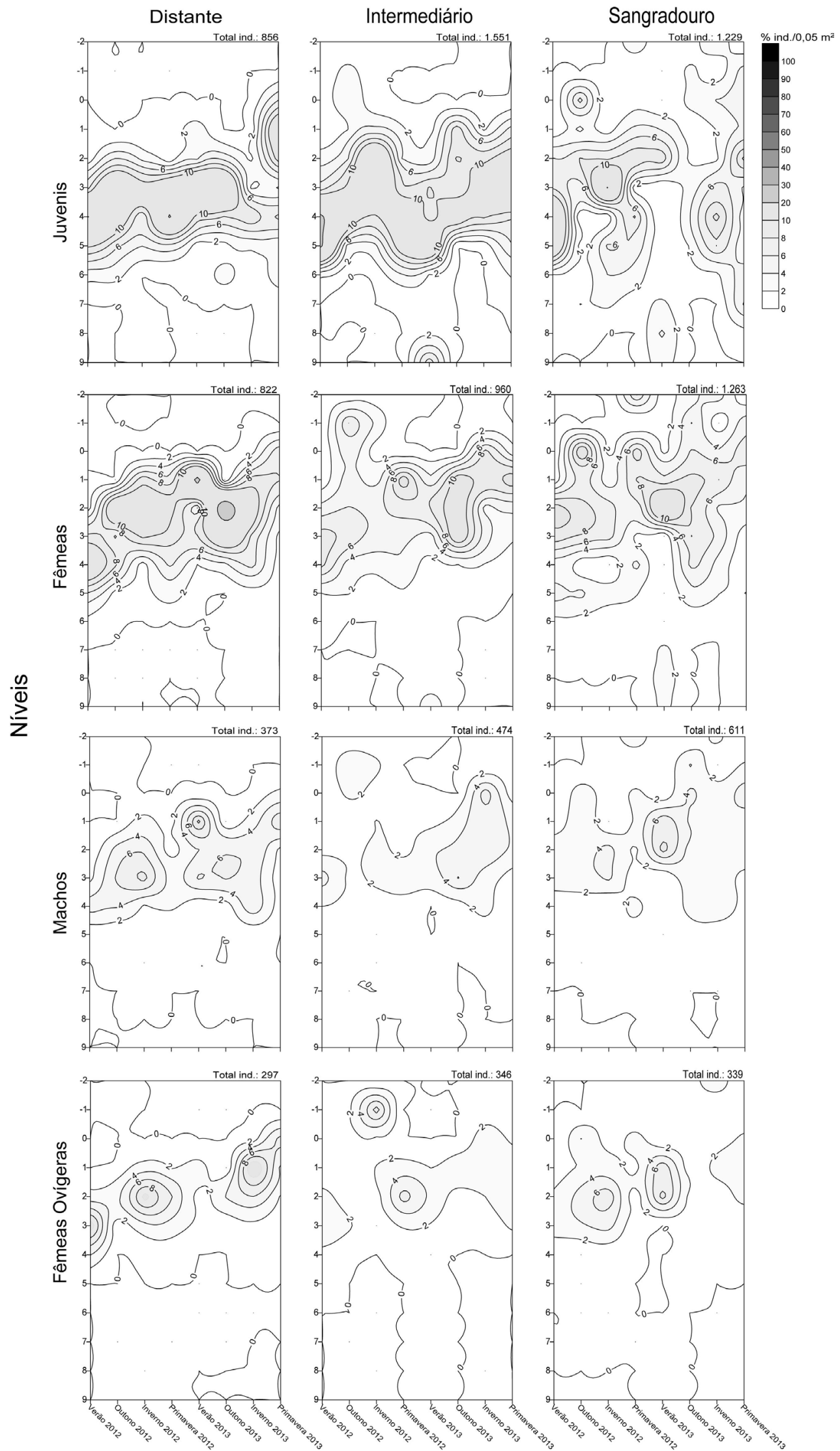

Fig. 9. Proporção das classes etárias de Tholozodium rhombofrontalis (GiambiaGi, 1922) (\% ind./0,05 $\mathrm{m}^{2}$ ) registradas nos três locais de coleta (distante, intermediário e sangradouro) ao longo dos níveis e das oito amostragens realizadas na praia de Barrancos, Paraná, Brasil. A proporção foi calculada através da fórmula: $\%$ classe $=(\mathrm{n} / \mathrm{N})^{*} 100$, onde $\mathrm{n}$ representa o número de indivíduos de cada classe em cada nível e $\mathrm{N}$ o número total de organismos medidos e sexados da transecção central de cada local e em cada coleta. 


\section{DISCUSSÃO}

A presença de um sangradouro permanente no ambiente praial produz constantes processos de transporte sedimentar e consequentemente provoca alterações no morfodinamismo local. Em particular na praia de Barrancos, mudanças no perfil associadas à suavização do grau de inclinação praial produziram condições mais dissipativas. Estas modificações na morfologia praial nas áreas adjacentes e também sob influência direta do sangradouro foram descritas por GANDARA-MARTINS et al. (2015).

De forma geral, os sedimentos resultaram homogêneos, grãos de areia fina e bem selecionados, corroborando com as descrições anteriores de Souza \& Gianuca (1995) e GANDARA-MARTINs et al. (2015) para a mesma praia. Por outro lado, a baixa porcentagem de carbonatos e de matéria orgânica ao longo dos locais e do tempo pode ser explicada pela distância do estuário de Paranaguá, o qual supostamente seria a principal fonte destas variáveis ambientais para a praia, visto que, as regiões estuarinas desempenham papel importante na transferência da matéria orgânica de origem terrestre para os ecossistemas marinhos (SCHLACHER \& Connolly, 2009).

Quanto à ocorrência de Tholozodium rhombofrontalis no litoral do Paraná, VIEIRA et al. (2012), no mesmo arco praial da praia de Barrancos, registraram este isópode associado a sedimentos compostos por areia fina e bem selecionados. Diversos estudos em outros ambientes diferentes de praias arenosas oceânicas relataram esta espécie associada a características observadas no presente trabalho, como solos constituídos de areia fina e águas salobras (Giambiagi, 1922; Loyola E Silva, 1960; Pires, 1982; Darrigran \& RiOJA, 1988; TABERNER, 1988; VAROLI, 1990; WÜRDIG \& Dornelles Da Silva, 1990; FlynN et al., 1998; BuCKuP \& BOND-BUCKUP, 1999; CÉsAR et al., 2000; BORZONE et al., 2003; Felix et al., 2015).

Outra espécie do mesmo gênero foi descrita em habitats similares na Índia. Tholozodium ocellatum foi correlacionado com sedimentos finos e grandes quantidades de detrito orgânico na praia (ElEFTHERIou et al., 1980). Neste trabalho os autores supõem que a relação entre a espécie e o sedimento fino pode estar ligado ao modo de vida fossorial, e a maior presença de T. ocellatum em ambientes com altas quantidades de detritos orgânicos teria relação com a proximidade a grandes estuários (ELEFTHERIOU et al., 1980). A praia de Barrancos, com seu perfil granulométrico de areia fina e bem selecionada, encontra-se fora da área de influência do delta de vazante do estuário de Paranaguá. No entanto, possui um sangradouro permanente que aporta água doce $\mathrm{e}$ detritos orgânicos da região do pós-dunas, representando um ambiente de transição entre o meio marinho e o meio límnico.

O escoamento da água doce da região do pós-dunas na parte superior da praia e a consequente diminuição da salinidade em quase todo o perfil praial é possivelmente uma das alterações mais significativas do ponto de vista biológico. Por outro lado, a concentração de clorofila $a$ parece depender diretamente das variações da salinidade, pela aparente preferência do microfitobentos por águas salobras. De fato, no presente estudo a maior abundância de $T$. rhombofrontalis esteve associada aos menores valores de salinidade.

ELEFTHERIOU et al. (1980) concluíram que o peracárida Tholozodium ocellatum apresenta uma dieta herbívora e possivelmente onívora. O isópode Sphaeromopsis amathitis Holdich \& Jones, 1973, pertencente à mesma família de $T$. rhombofrontalis, foi considerado herbívoro a partir de análises do conteúdo estomacal de alguns indivíduos coletados em praias arenosas do Quênia, país localizado na África Oriental (HoLDich \& JoNEs, 1973). No presente trabalho observaram-se maior abundância de T. rhombofrontalis em locais com altas concentrações de clorofila $a$ no sedimento, o que indica uma provável dieta herbívora para esta espécie descrita apenas para alguns países da América do Sul, como a Argentina, o Uruguai e o Brasil, neste último apenas nos estados de São Paulo, Paraná, Santa Catarina e Rio Grande do Sul.

Desta forma, a salinidade e a concentração de clorofila $a$ são reconhecidos como parâmetros fundamentais na abundância e distribuição do isópode nesta praia. Por um lado, a salinidade pode interferir nas trocas osmóticas entre o meio externo e interno do indivíduo com efeitos na fisiologia do mesmo, e por outro a concentração de clorofila $a$ pode ditar a disponibilidade do recurso alimentar para a população.

Com relação à distribuição espacial ao longo do perfil praial, os resultados mostraram o mesmo padrão obtido por Souza \& GianuCA (1995), com as maiores abundâncias de $T$. rhombofrontalis nos níveis que correspondem à zona mediolitoral superior (DAHL, 1952).

A presença de todas as classes etárias nos três locais amostrados demonstra a existência de uma população permanente de $T$. rhombofrontalis em toda a área de estudo. A dominância de indivíduos juvenis ao longo do tempo indica um recrutamento contínuo e independente das características ambientais de cada local. Contudo, a diminuição de indivíduos juvenis no local sangradouro e nos níveis inferiores dos locais distante e intermediário poderia ser explicada pelas características morfológicas e etológicas inerentes a este estágio de desenvolvimento. Quando comparados aos indivíduos adultos, os juvenis apresentam tamanho reduzido, o que compromete sua eficiência de escavação e enterramento, atividades fundamentais para a permanência em ambientes com fluxo de água constante, como é o caso do local sangradouro.

As fêmeas apresentaram proporções semelhantes ao longo das estações e dos anos, confirmando a estabilidade espaço-temporal desta população. Diferentemente da abundância de juvenis e fêmeas, a proporção de machos foi reduzida em todos os locais amostrados e durante todas as coletas. Aparentemente tal fato não teve efeito negativo para o estabelecimento desta população na praia de Barrancos e poderia representar uma característica intrínseca da espécie. Apesar da abundância reduzida, todos os indivíduos machos apresentaram tamanho maior que o das fêmeas. TABERNER (1988) concluiu que o tamanho do macho de $T$. 
rhombofrontalis pode superar em até $1 / 3$ o da fêmea, o que também foi constatado no presente trabalho. Alguns estudos relacionados a crustáceos marinhos indicam que o tamanho dos machos é maior que o das fêmeas, porém os machos são menos abundantes que as fêmeas (WENNER, 1972), como aqui também registrado.

As fêmeas ovígeras demonstraram baixa proporção em todos os locais e em todas as coletas. Padrões similares foram encontrados para Excirolana braziliensis Richardson, 1912, que também apresentou um número reduzido de fêmeas ovígeras no ambiente estudado (ZuÑIGA et al., 1985). Contudo, o local distante mostrou maior proporção de fêmeas ovígeras no inverno dos dois anos, o que poderia indicar preferência por uma estação mais fria para o período de reprodução. Nos locais intermediário e sangradouro este padrão invernal aparece somente para o ano de 2012.

PIRES (1982) descreveu pela primeira vez a morfologia da fêmea de $T$. rhombofrontalis apontando uma bolsa interna no corpo da fêmea onde os ovos se desenvolvem. Segundo Lozoya \& Defeo (2006) é considerada a hipótese de que o desenvolvimento interno dos estágios embrionários de Excirolana armata (Dana, 1853), outro isópode muito comum em praias arenosas, fornece proteção à prole contra a dessecação e estresse osmótico, por exemplo, causado pelas variações da salinidade ocasionadas pela descarga de água doce. A descrição da bolsa interna nas fêmeas ovígeras de $T$. rhombofrontalis e a comparação com o peracárido $E$. armata fornecem evidências de que este tipo de desenvolvimento interno favorece a colonização de T. rhombofrontalis em distintos ambientes, uma vez que os ovos e os embriões ficam protegidos das variações de salinidade e de outros fatores ambientais, como foi observado neste trabalho, onde as fêmeas ovígeras estiveram em todos os locais de coleta.

A maior parte dos indivíduos coletados foi capturada no estágio de curvamento do corpo com a finalidade de formar uma esfera, processo denominado de volvação, o qual permite a proteção da superfície ventral e a manutenção da umidade, outra característica de proteção da espécie, como também observado para o isópode terrestre Tylos niveus Budde-Lund, 1885 (Loyola E Silva \& Alves, 2000). Tais adaptações morfológicas aliadas à estratégia de desenvolvimento interno podem justificar a ampla distribuição e sua alta capacidade de sobrevivência.

Considerando os resultados obtidos neste estudo, conclui-se que Tholozodium rhombofrontalis é uma espécie eurialina, que provavelmente possui uma dieta herbívora e que pode ocupar diferentes ecossistemas. Algumas características ambientais, assim como sedimentos compostos de areia fina, grãos bem selecionados, águas salobras e altas concentrações de clorofila $a$, são aspectos fundamentais para o estabelecimento de populações desta espécie.

Agradecimentos. Ao Programa de Pós-Graduação em Sistemas Costeiros e Oceânicos (PGSISCO/UFPR) pelo apoio ao trabalho e à Coordenação de Aperfeiçoamento de Pessoal de Nível Superior (CAPES) pela concessão da bolsa de mestrado (2015-2017).

\section{REFERÊNCIAS BIBLIOGRÁFICAS}

Angulo, R. J. \& AraúJo, A. D. 1996. Classificação da costa paranaense com base na sua dinâmica, como subsídio a ocupação da orla litorânea. Boletim Paranaense de Geociências 44:7-17.

Borzone, C. A. \& SouzA, J. R. B. 1997. Estrutura da macrofauna bentônica no supra, meso e infralitoral de uma praia arenosa do sul do Brasil. Oecologia Brasiliensis 3(1):197-212.

Borzone, C. A.; Melo, S. G.; Rezende, K. V.; do Vale, R. \& Krul, R. 2003. Macrobenthic intertidal communities from wave to tide dominated beach environments. A case study in two Brazilian beaches. Journal of Coastal Research 35:472-480.

Borzone, C. A.; Souza, J. R. B. \& Soares, A. G. 1996. Morphodynamic influence on the structure of inter and subtidal macrofaunal communities of subtropical sandy beaches. Revista Chilena de História Natural 69:565-577.

Boschi, E. E. 1988. El ecosistema estuarial del Río de la Plata (Argentina y Uruguay). Anales del Instituto de Ciencias del Mar y Limnología de la Universidad Nacional Autónoma de México 15:159-182.

BrazeIRo, A. \& DEFEO, O. 1996. Macroinfauna zonation in microtidal sandy beaches: is it possible to identify patterns in such variable environments? Estuarine, Coastal and Shelf Science 42(4):523-536.

Buckup, L. \& Bond-Buckup, G. 1999. Os crustáceos do Rio Grande do Sul. Porto Alegre, Editora da Universidade Federal do Rio Grande do Sul. 503p.

César, I; Ocón, C.; Paggi, A. C.; Rodrigues, A.; Spaccesi, F.; Tangorra, M. \& TAssara, M.2000. Diversidad de invertebrados bentónicos del Río de la Plata. Biología Acuática 19:27-63.

Cisneros, K. O.; Smit, A. J.; Laudien, J. \& Schoeman, D. S. 2011. Complex, dynamic combination of physical, chemical and nutritional variables controls spatio-temporal variation of sandy beach community structure. PloS One 6(8):e23724.

CochôA, A. R.; Lorenzi, L. \& Borzone, C. A. 2006. A influência da passagem de uma frente meteorológica na distribuição da macrofauna bentônica mesolitoral de uma praia arenosa exposta. Tropical Oceanography 34(2):59-71.

Cressie, N. 1990. The origins of kriging. Mathematical Geology 22(3):239252.

DAHL, E. 1952. Some aspects of the ecology and zonation of the fauna on sandy beaches. Oikos 4(1):1-27.

DARrigran, G. A. \& RioJA, S. I.1988. Distribución y selección de ambientes de los isópodos talasoides del Río de la Plata, República Argentina. Neotrópica 36:105-114.

Dugan, J. E. \& McLachlan, A. 1999. An assessment of longshore movement in Donax serra Röding (Bivalvia: Donacidae) on an exposed sandy beach. Journal of Experimental Marine Biology and Ecology 234(1):111-124.

Eleftheriou, A.; Holdich, D. M. \& Harrison, K. 1980. The systematics and ecology of a new genus of isopod (Sphaeromatidae) from the west coast sandy beaches of India. Estuarine and Coastal Marine Science 11(3):251-262.

Felix, G.; Cândido, T. F.; Silveira, C. B. \& Netto, S. A. 2015. Resposta de associações bênticas ao lançamento de resíduos de drenagem urbana. Brazilian Journal of Aquatic Science and Technology 19(2):47-56.

Flynn, M. N.; WaKabara, Y. \& Tararam, A. S.1998. Macrobenthic associations of the lower and upper marshes of a tidal flat colonized by Spartina alterniflora in Cananéia lagoon estuarine region (southeastern Brazil). Bulletin of Marine Science 63(2):427-442.

Gandara-Martins, A. L.; Borzone, C. A.; Guilherme, P. D. \& Vieira, J. V. 2015. Spatial effects of a washout on sandy beach macrofauna zonation and abundance.Journal of Coastal Research 31(6):1459-1468.

Giambiagi, D. 1922. Cuatro nuevos isópodos de la Argentina. Physis 5(20):230-244.

Holdich, D. M. \& Jones, D. A. 1973. The systematics and ecology of a new genus of sand beach isopod (Sphaeromatidae) from Kenya. Journal of Zoology 171(3):385-395.

Lercari, D.; Defeo, O. \& Celentano, E. 2002. Consequences of freshwater canal discharge on the benthic community and its habitat on an exposed sandy beach. Marine Pollution Bulletin 44(12):1397-1404. 
LeRCARI, D. \& DeFEO, O. 2003. Variation of a sandy beach macrobenthic community along a human-induced environmental gradient. Estuarine, Coastal and Shelf Science 58:17-24.

LerCARI, D. \& DeFEo, O.2006. Large-scale diversity and abundance trends in sandy beach macrofauna along full gradients of salinity and morphodynamics. Estuarine, Coastal and Shelf Science 68(1-2):27-35.

Loyola E SiLVA, J. 1960. Sphaeromatidae do litoral brasileiro. Boletim da Universidade do Paraná 4:1-182.

Loyola e Silva, J. \& Alves, E. S. 2000. Tylos niveus Budde-Lund, 1885 (Crustacea: Isopoda: Oniscidea: Tylidae): redescrição e nova ocorrência para a praia de Taquaras, Santa Catarina, Brasil. Acta Biológica Paranaense 29:265-285.

LozoyA, J. P. \& Defeo, O. 2006. Effects of a freshwater canal discharge on an ovoviviparous isopod inhabiting an exposed sandy beach. Marine and Freshwater Research 57(4):421-428.

McLachlan, A.1996. Physical factors in benthic ecology: effects of changing sand particle size on beach fauna. Marine Ecology Progress Series 131:205-217.

Pereira da Silva, R.; Calliari, L. J. \& de Morais Tozzi, H. A. 2003. The influence of washouts on the erosive susceptibility of Rio Grande do Sul between Cassino and Chuí beaches, Southern Brazil. Journal of Coastal Research 35:332-338.

PIRES, A. M. S. 1982. Sphaeromatidae (Isopoda: Flabellifera) da zona entre marés e fundos rasos dos Estados de São Paulo e Rio de Janeiro. Boletim do Instituto Oceanográfico 31(2):43-55.

SANDRINI-Neto, L. \& CAMARGo, M. G.2011. GAD: an R package for ANOVA designs from general principles. Available on CRAN. Vienna, R Foundation for Statistical Computing.

SANTOS, P. J. P. 1991. Morphodynamical influence of a temporary freshwater stream on the population dynamics of Scolelepis gauch (Polychaeta: Spionidae) on a sandy beach in southern Brazil. Bulletin of Marine Science 48(3):657-664.

SCHLACHER, T. A. \& ConNolly, R. M. 2009. Land-ocean coupling of carbon and nitrogen fluxes on sandy beaches. Ecosystems 12(2):311-321.

Schoeman, D. S. \& Richardson, A. J. 2002. Investigating biotic and abiotic factors affecting the recruitment of an intertidal clam on an exposed sandy beach using a generalized additive model. Journal of Experimental Marine Biology and Ecology 276(1-2):67-81.

SHORT, A. D. 1999. Handbook of beach and shoreface morphodynamics. London, John Wiley. 46p.

SouZA, J. R. B. \& GiANUCA, N. M. 1995. Zonation ans seasonal variation of the intertidal macrofauna on a sandy beach of Paraná State, Brazil. Scientia Marina 59(2): 103-111.

Strickland, J. D. H. \& Parsons, T. R.1972. A practical handbook of seawater analysis. Bulletin Fisheries Research Board of Canada 167:1-205.

TABERNER, R. 1988. Sobre Ias espécies de água dulce de Ia familia Sphaeromatidae (Isopoda, Flabellifera) I: Basphaeroma rhombofrontale (Giambiagi, 1922). Physis 46:21-27.

UNDERWOOD, A. J. 1997. Experiments in Ecology: Their logical design and interpretation using analysis of variance. Cambridge, Cambridge University Press. 504p.

VALENTIN, J. L. 2000. Ecologia numérica: uma introdução à análise multivariada de dados ecológicos. Rio de Janeiro, Interciência. 117p.

VAROLI, F. M. F. 1990. Avaliação da macrofauna bentônica da zona entremarés em dois baixios do sistema estuarino-lagunar de Iguape-Cananéia. Bioikos 4(2):24-39.

Vieira, J. V.; Borzone, C. A.; Lorenzi, L. \& Carvalho, F. G. D. 2012 Human impact on the benthic macrofauna of two beach environments with different morphodynamic characteristics in southern Brazil. Brazilian Journal of Oceanography 60(2):137-150.

Wells, R. G. \& Daborn, G. R. 1998. Río de la Plata; una revisión ambiental: un informe de antecedentes del proyecto EcoPlata, julio 1997. Nueva Escocia, Universidad de Dalhousie. 256p.

WenNER, A. M. 1972. Sex ratio as a function of size in marine crustacea. The American Naturalist 106(949):321-350.

Würdig, N. L. \& DorNelleSDA SILVA, C. M.1990. Distribuição e abundância da comunidade de Isopoda na Lagoa do Gentil, sistema lagunar de Tramandaí, RS. Acta Limnologica Brasiliensia 3:785-806.

Zuñiga, O.; Pena, R. \& Clarke, M. 1985. Historia de vida y produccion de Excirolana braziliensis Richardson, 1912 (Isopoda: Cirolanidae). Estudios Oceanológicos 4:9-19. 